\title{
Saúde mental, arte e desinstitucionalização: um relato estético-poético-teatral de uma ocupação da cidade
}

\author{
Mental health, art, and deinstitutionalization: \\ an aesthetic-poetic-theatrical account of the city's occupation
}

Júlia Monteiro Schenkel (https://orcid.org/0000-0001-6975-7173) ${ }^{1}$

Glauber Weder dos Santos Silva (https://orcid.org/0000-0002-0570-1944) ${ }^{2}$

Ana Karenina de Melo Arraes Amorin (https://orcid.org/0000-0002-1343-9341) ${ }^{3}$

Francisco Arnoldo Nunes de Miranda (https://orcid.org/0000-0002-8648-811X) ${ }^{4}$

Jovanka Bittencourt Leite de Carvalho (https://orcid.org/0000-0002-0785-3423) ${ }^{5}$

Sara Eloise Argimiro Ribeiro (https://orcid.org/0000-0003-0890-3426) ${ }^{4}$

Ana Clara Paiva de Almeida (https://orcid.org/0000-0003-3969-1868) ${ }^{4}$

Maxwell Menezes Silva (https://orcid.org/0000-0003-2380-8742) ${ }^{6}$

\footnotetext{
${ }^{1}$ Programa de PósGraduação em Psicologia, Universidade Federal do Rio Grande do Norte. Campus Universitário Lagoa Nova, Caixa Postal 1622. 59078-970 Natal RN Brasil. juliamonteiroschenkel@ gmail.com

${ }^{2}$ Direção de Enfermagem, Hospital Giselda Trigueiro, Secretaria de Saúde Pública do Rio Grande do Norte. Natal RN Brasil.

${ }^{3}$ Departamento de Psicologia, Universidade Federal do Rio Grande do Norte. Natal RN Brasil. ${ }^{4}$ Departamento de Enfermagem, Universidade Federal do Rio Grande do

Norte. Natal RN Brasil.

${ }^{5}$ Escola de Saúde,

Universidade Federal do Rio Grande do Norte. Natal RN Brasil.

${ }^{6}$ Centro de Convivência e Cultura de Natal, Secretaria Municipal de Saúde de Natal. Natal RN Brasil.
}

\begin{abstract}
This study aimed to report the experience of an aesthetic, poetic, and theatrical production of the city's occupation from a device of the Psychosocial Care Network to offer space for sociability, production, and cultural intervention. This is an account of an experience from the Social and Cultural Center (CECCO) in Natal, Rio Grande do Norte, Brazil, within madness and mental health deinstitutionalization. The intervention "The Little Prince occupies the Ribeira" was inspired by the work of author Saint-Exupéry. The artistic and creative acts reported occurred in December 2019. We experienced in this intervention the reach of an aesthetic clinic that, when opened to the street and art, expanded and weaved in the territory, instrumentalized by theater, dance, poetry, percussion, crafts, and city's occupation. The movement led the community to "step down from the stage" to the streets and is connected with the twist of the asylum model and the production of the affection clinic that we seek to sustain in the daily service.
\end{abstract}

Key words Mental health, Art, Deinstitutionalization, Popular culture, Cities
Resumo Objetivou-se relatar a experiência de uma produção estética, poética e teatral de ocupação da cidade a partir de um dispositivo da Rede de Atenção Psicossocial, com vistas a oferecer espaço de sociabilidade, produção e intervenção cultural. Trata-se de um relato de experiência a partir do Centro de Convivência e Cultura (CECCO) de Natal, Rio Grande do Norte, Brasil, dentro do campo da desinstitucionalização da loucura e da saúde mental. A intervenção urbana "O Pequeno Príncipe ocupa a Ribeira" foi inspirada na obra do escritor Saint-Exupéry. Os atos artísticos e criativos relatados aconteceram em dezembro de 2019. Experimentamos nessa intervenção os alcances de uma clínica-estética que, ao se abrir para a rua e para a arte, se amplia e se tece no território, instrumentalizado pelo teatro, dança, poesia, percussão, artesanato e ocupação da cidade. O movimento gerou no coletivo um "descer do palco" em direção à rua e se conecta com a desconstrução do modelo manicomial e produção da clínica dos afetos que buscamos sustentar no cotidiano do serviço.

Palavras-chave Saúde mental, Arte, Desinstitucionalização, Cultura popular, Cidades 


\section{Notas introdutórias}

A experiência que iremos relatar se deu a partir do Centro de Convivência e Cultura de Natal (CECCO), em Natal, Rio Grande do Norte, Brasil, serviço da rede municipal de saúde que compõe a Rede de Atenção Psicossocial, em parceria com o Projeto de Extensão "Grupo Tons de Vida: oficinas artísticas, teatro popular e saúde mental na cidade a partir do Centro de Convivência e Cultura de Natal-RN", do Departamento de Enfermagem da Universidade Federal do Rio Grande do Norte (UFRN), e com o apoio da Fundação Cultural Capitania das Artes (FUNCARTE).

Como espaços híbridos entre saúde, arte e cultura, os Centros de Convivência e Cultura surgiram no Brasil como dispositivos que compõem a Rede de Atenção Psicossocial (RAPS) para oferecer espaços de sociabilidade, produção cultural e intervenção na cidade. Estrategicamente, foram pensados como serviços abertos e não exclusivamente voltados às pessoas que usam a RAPS ${ }^{1}$. Tais serviços têm se mostrado como importante dispositivo nas redes de atenção à saúde para a promoção de encontros e articulação do cuidado com a vida cotidiana e seus processos de criação, alinhados ao paradigma da reforma psiquiátrica ${ }^{2}$.

Se na Reforma Psiquiátrica há um aspecto que pouco avançou desde 2001, ano marco de promulgação da Lei Paulo Delgado 3 , este seria a dimensão sociocultural da desinstitucionalização em deslocar os sentidos sociais atribuídos à loucura e à diferença na vida social. Desmistificar esse lugar que persiste marcado por estigmas e preconceitos ligados a noções de incapacidade e periculosidade, e que, justamente por isso, acabam produzindo territórios afetivos despotencializados e geradores de exclusão e sofrimento psíquico, segue como uma tarefa para as Redes de Atenção Psicossocial (RAPS).

Os dispositivos da RAPS atuam como intermediadores dos sujeitos com o mundo social que os circunda, os quais primam por iniciativas criativas que contemplem os diversos modos de existir e viver com o sofrimento psíquico, conectando-os com a comunidade/cidade. As atividades desenvolvidas no âmbito da RAPS buscam desenvolver a dimensão pessoal e social a partir das diferentes necessidades dos usuários ${ }^{4}$.

Entendemos, portanto, que para enfrentar e resistir à reprodução da lógica manicomial que insiste na tecla da exclusão e do preconceito, as políticas de saúde mental não podem resignarse nas clausuras de seus serviços de saúde, nem mesmo se bastar nos emaranhados de suas redes formais e nos espaços privados do território da clínica, mas precisam se ampliar na relação com a cidade e a cultura ${ }^{5}$.

É no espaço cultural que a Reforma Psiquiátrica pode alcançar êxito, pois a mudança do modelo de atenção em saúde mental e o combate ao preconceito, estigma e segregação dispensados historicamente à loucura, se opera na construção de novos lugares sociais para o "louco", na sustentação de um paradigma social de protagonismo e cidadania para o usuário e seus familiares ${ }^{6}$.

Ao nos posicionarmos eticamente recusando a reprodução de práticas excludentes e investirmos na criação de estratégias para a desinstitucionalização da loucura e de afirmação da diferença na cidade, apontamos para a potência da arte na clínica antimanicomial e na sua contribuição para diversificar a experiência dos encontros dos usuários da RAPS com e na cidade $^{7}$. Nesse sentido, experiências recentes têm apontado para um descolamento da arte como dispositivo estritamente terapêutico, e se tornado uma estratégia de produção de projetos de vida e desinstitucionalização da loucura na vida social em sentido amplo ${ }^{8}$. Segundo Pelbart ${ }^{9}$, é possível conceber a arte como ingrediente importante na produção de saúde e vida desses sujeitos, uma vez que a loucura em sua força biopolítica exige a construção de "dispositivos multifacéticos, ao mesmo tempo políticos, estéticos, clínicos na reinvenção das coordenadas de enunciação da vida"' (p. 37).

É nessa direção que deixamos de lado o termo usuários, por vezes banalizado no Sistema Único de Saúde, e referimo-nos aos frequentadores do CECCO como convivas, marcando assim uma tentativa de deslocamento na relação deles com o Centro e com os trabalhadores da equipe. Afirma-se, assim, a potência da lateralidade, porém sem negligenciar as diferenças e singularidades nas funções e responsabilidades. Somos todos convivas, criando juntos formas de conviver e de habitar a cidade.

Esse movimento se dá de diferentes formas: através da participação ou organização de feiras para exposição do artesanato produzido nas oficinas, de eventos onde apresentações artísticas são realizadas (dança, percussão, grupo vocal, teatro), bem como na ocupação de outros espaços que auxiliem na valorização da arte produzida pelos convivas e em sua divulgação. Essa é a atuação clínico-política que o CECCO vem desenvolvendo no município de Natal com fortalecimento da inserção dos convivas na cidade, estimulando a ocupação dos espaços públicos, 
e levando sua produção artística e cultural para além dos muros do serviço.

\section{O Centro de Convivência e Cultura de Natal-RN e sua intersetorialidade}

Inaugurado em agosto de 2017, o CECCO de Natal vem se consolidando na cidade como um importante espaço da Rede de Atenção Psicossocial, lugar de encontros, de acolhimento e de acesso a atividades artísticas e culturais, tendo como público-alvo, mas não exclusivo, os usuários da RAPS. Esse movimento se sustenta a partir da articulação dos diferentes atores sociais, que, para além da equipe vinculada ao serviço, agrega colaboradores vindos de outros trabalhos da RAPS, artistas do território que realizam trabalho voluntário, estudantes e professores que buscam o serviço como espaço de formação.

São ofertadas diversas oficinas, dentre elas: dança, percussão, poesia, violão, artesanato, teatro, grupo vocal, alongamento, meditação, além das atividades programadas que buscam ampliar a ocupação de espaços e inserção dos convivas na cidade. Tais atividades desenham uma rotina mutante de ofertas quotidianas, que vão sendo construídas conforme a disponibilidade dos atores que compõe o coletivo e o desejo dos convivas. Para além das oficinas, o CECCO é vivenciado por seus frequentadores como "um lugar para fazer amizades" e de "descobrir capacidades que não sabia que tinha" - expressões muitas vezes utilizadas por eles.

Há uma busca do CECCO em constituir-se como um espaço de liberdade onde os convivas possam frequentar a partir do desejo e se relacionarem com as atividades de modo singular e não como uma necessidade imposta por um tratamento. Mais do que usar a arte como útil para o tratamento em saúde mental, buscamos explorar a inutilidade da arte como potente na criação de uma estilística da existência, que faça frente a institucionalização da loucura com suas capturas diagnósticas e psiquiatrizantes (ou mesmo psicologizantes $)^{10}$.

Dessa forma, há os que vão para realizar atividades e há os que não realizam oficina nenhuma, como o conviva da rua que dorme no sofá, ou aquele que vai aguar as plantas, o que vai alimentar os gatos das redondezas, aquele que apenas participa da roda de abertura das atividades e logo vai embora, ou também aquele que fica mais pelos corredores ou na sala de jogos...são múltiplas as formas de conexão que cada conviva vai criando com o serviço.
É nesse contexto de trabalho que diversas oferendas culturais puderam ser apresentadas para a cidade ao longo dos três anos de existência do CECCO, como a produção teatral do Auto de $\mathrm{Na}$ tal em 2018; a realização do $1^{\circ}$ LeiloArte em uma galeria de arte e o lançamento do Cordel Poetas Convivas em um espaço cultural tradicional da cidade, ambos na semana de comemoração dos dois anos de existência do CECCO em agosto de 2019 e, mais recentemente o circuito estético-poético-teatral "O Pequeno Príncipe Ocupa a Ribeira", realizado em dezembro de 2019 - experiência que buscaremos compartilhar através dessa escrita.

Ao situarmos tal experiência dentro do campo da desinstitucionalização da loucura e da saúde mental, entendemos que não apenas a loucura precisa ser desinstitucionalizada, mas também o próprio campo da saúde mental e suas políticas. Ou seja, para a atenção psicossocial operar a substituição, ou melhor, a subversão da lógica manicomial, é necessário não apenas a criação e sustentação de uma rede de serviços de cuidados territoriais que disputem o lugar e os sentidos da loucura e da diferença na cidade, mas também que a própria RAPS crie formas de se conectar com outros saberes, para fora do campo da saúde mental, abrindo e transversalizando a clínica. Apontamos para a arte e para a rua como estratégicas nessa direção, para produção de fragmentos estéticos que não se reproduzem como roteiros e constituem-se como momentos singulares e privilegiados entre saúde e loucura, extinguindo os limites entre arte e vida, arte e não-arte ${ }^{11}$.

$\mathrm{O}$ que torna uma manifestação artística um ato político? O que faz um serviço de Atenção Psicossocial de fato se posicionar clínica e politicamente na disputa pelos lugares sociais atribuídos socialmente à loucura e à diferença? Sem a pretensão de responder a essas questões, mas as deixando reverberar como pano de fundo para o relato de experiência a ser aqui compartilhado, defendemos que essa passagem se dá justamente na ocupação do espaço público, na passagem do território privado da clínica para o espaço público da cidade: "é quando o bloco vai pra rua..."

Se espaços asilares e manicomiais operam a violência de arrancar as pessoas de seus locais de existência em nome da palavra de ordem de um tratamento, desinstitucionalizar passa pelo investimento nas relações com os diferentes territórios de vida das pessoas e pela criação de novos territórios de existência capazes de potencializar suas vidas. Dessa forma, narrar essa história, esse relato de experiência sobre essa intervenção estética 
na cidade, convoca a narrativa sobre o território onde deu-se tal ocupação.

\section{Território e narrativa de um processo de construção coletiva}

O CECCO ocupava a Ribeira, bairro histórico da cidade de Natal, onde a cidade começou a se desenvolver, ao lado do Rio Potengi. Território de intensa atividade comercial e portuária, aonde no início do Século XX recebeu o investimento de uma cidade que queria se modernizar. Bares, cafés, lojas de luxo, cabarés... “Uma Natal moderna, civilizada e elegante, que desejava se assemelhar à Paris da Belle Èpoque"12.

De local privilegiado até se tornar um espaço de abandono e desinvestimento do poder público, temos um século de história que podemos sentir ao contemplar as fachadas dos inúmeros prédios tombados que em sua maioria se deterioram com o passar dos anos. O desinvestimento do Porto de Natal, ocasionado pelo enfraquecimento do transporte fluvial, parece deixar o bairro 'a ver navios', excetuando alguns movimentos e espaços culturais que ainda ocupam esse território. Este é o lugar que surgiu para o CECCO como propício para operar uma ação de ocupação da cidade e desinstitucionalização da loucura. Afinal, para corpos excluídos por uma sociedade normatizada, a luta contra o descaso e o abandono é infelizmente um território conhecido.

\section{A provocação para um encontro cultural}

Neste mesmo espaço da cidade, a partir da relação do CECCO com a Galeria de chamada B-612, recebemos um convite para participarmos de um evento em homenagem à obra $O$ Pequeno Príncipe de Saint-Exupéry. Acionamos o Projeto de Extensão que já desenvolvia oficinas de teatro no serviço e assim teve início o encontro dos convivas e do CECCO com esse clássico livro que narra aventuras e afetos de um menino que ousa ir além de seu próprio planeta.

A aproximação e o campo de tensão com a clássica obra de Antoine de Saint-Exupéry foi se dando através de grupos de leitura e discussão do livro, exibição de película cinematográfica ${ }^{13}$, produção de desenhos e poesias e nesse processo coletivo de produção, fomos nos apropriando dessa estória e singularizando-a a partir das conversas, pensamentos e reflexões que o encontro com o texto do Pequeno Príncipe despertavam: “- E se o pequeno príncipe caísse na cidade de Natal"?"; - E se a gente fizesse um país da medicalização?";
“- Mas porque o pequeno príncipe foi embora de seu planeta abandonando a rosa?"; “- Nunca abandone aquilo que você ama”...essas e outras questões e outros “e se (...)" foram se dando nessa construção entre os convivas.

Posteriormente, todas as oficinas do serviço se voltaram para essa produção cultural, envolvendo as oficinas de poesia, artesanato, dança, percussão, transformado o cotidiano do serviço e dos convivas. Apesar de contarmos com vários oficineiros artistas, a oficina de teatro do CECCO era desenvolvida por um Enfermeiro executor do projeto de extensão já mencionado acima, afetado por outras experiências cênicas. Também colaboravam os estudantes de Graduação em Enfermagem orientados por ele, com o apoio da equipe do CECCO. Na construção coletiva desse processo, fomos percebendo que era necessário expandir para além das nossas capacidades enquanto profissionais da saúde e convocar outros atores ligados diretamente às artes cênicas.

Com a chegada de um diretor de teatro, trabalhador da Secretaria Municipal de Cultura e funcionário da FUNCART, a nossa proposta de produção de uma "peça teatral" ganhou novos contornos criativos e imagéticos e passamos a explorar a ideia de intervenção-estética na cidade.

\section{Intervenção estética como estratégia de desinstitucionalização: \\ fragmentos de uma ocupação urbana}

Se no ano anterior o CECCO havia ocupado um teatro da cidade e realizado um espetáculo (Auto de Natal), em nossa experiência aqui relatada, o parceiro das artes cênicas não assumiu o lugar tradicional de diretor de teatro, mas desacomodou-nos da ideia inicial de produzir um roteiro, falas e uma peça teatral, e nos convocou a produzir interferências na rotina da cidade em um circuito cultural que fosse para a rua. Diversas ações foram se desenhando, algumas ganharam força e corpo, outras não se concretizaram. Importava olhar para o que adquiriria uma certa velocidade e o que faria sentido ou não para os convivas.

Abandonamos a ideia tradicional de palco, na qual público e atores estão bem separados e demarcados e passamos a construir uma ocupação artística urbana, na qual efeitos estéticos são produzidos em encontros não previstos e inusitados pela cidade. Mas, como os convivas queriam atuar, acolhemos esse desejo e produzimos com eles algumas cenas (que abaixo no texto serão descritas) e então fomos compondo nosso circui- 
to entre esquetes teatrais, intervenções urbanas e tudo mais que o CECCO tinha para expressar: dança, percussão, artesanato, rádio livre, pintura no muro... Uma explosão de linhas expressivas e artísticas tomando as ruas da Ribeira, gerando encontros inusitados com os transeuntes e com o comércio local. Caracterizamos a ocupação como "intervenção urbana" a partir do sentido proposto por Lima ${ }^{11}$ (p. 13):

Localizada na intersecção entre arte e política, a intervenção urbana pode ser entendida como uma forma de linguagem muito abrangente e diversificada que se manifesta em espaços públicos, tendo como principal característica a utilização da própria cidade, e de seus elementos pré-existentes, como plataforma para a realização dessas intervenções (...) Desta forma, são entendidas como intervenção urbana as mais diferentes formas de interação com elementos que constituem a paisagem urbana, que considerem a cidade como uma grande tela que sirva de suporte, motivação e até mesmo personagem para sua realização, extrapolando inclusive as fronteiras da arte e da ação política.

A rua foi fechada temporariamente, o trânsito cotidiano interrompido, fluxos urbanos bifurcados, nosso bando de convivas se misturando com o público que acompanhava o Circuito, além dos passantes que aleatoriamente se depararam com esse evento em seu percurso quotidiano na cidade e pararam para ver-viver "nossa banda passar" e alguns conosco a caminhar...Flores e estrelas multicoloridas e flores produzidas a partir de bulas de medicamentos foram espalhadas pelo trajeto do circuito, estrategicamente colocadas em lugares inusitados para que, quem sabe, fossem resgatadas por alguém em algum outro tempo.

A ocupação-intervenção urbana realizada também pode ser caracterizada a partir do chamado teatro de rua. Este consiste na invasão do ambiente cotidiano por produções artísticas e cênicas, de forma a interferir na rotina, causar estranhamentos e a ressignificação do espaço, da população presente e da cultura já estabelecidos. A invasão das ruas permite que se alcance um público diferente, aquele que não procura ou não possui acesso ao teatro, e vai além: permite que esse público dialogue com a arte, se torne também parte do teatro e seja capaz de atribuir novos sentidos ao que se apresenta. Trata-se de uma manifestação sociopolítica que busca gerar impacto, sensibilizar o público, causar inquietações e reflexões a respeito do tema retratado. Desta forma, o espaço e todos os participantes deste tipo de intervenção, atores e espectadores, são por ela afetados e transformados ${ }^{14-15}$.
Apresentaremos a experiência do Circuito em cinco atos, entre inúmeros que foram se produzindo coletivamente, buscando resgatar tempos de experimentação dos convivas como leitores (havia não leitores no grupo, e a leitura deu-se de forma coletiva com os leitores emprestando os olhos e vozes para os não leitores), atores, dançarinos, roteiristas e mesmo como diretores.

\section{Afetações no contexto de produção e criação}

Dona Flor (nome fictício), uma das não leitoras, mulher negra, mãe de um conviva, se apropriou tão profundamente da obra, que em certo dia de ensaios, ela entra na sala no horário de intervalo e começa a recitar. Ela havia decorado todas as falas de uma das cenas no livro. Essa mesma conviva se experimenta como roteirista e narra/cria uma das cenas que ganhou corpo como o "Planeta das Mulheres Rendeiras".

Entendemos que esse espaço para o protagonismo e para a criação é, em si, o fundamento da ética de um cuidado antimanicomial que passa a funcionar quando passamos a apostar e a investir na capacidade de criação, na potência! Ou seja, a intervenção é criada de modo a que os corpos ali afirmem a sua potência de vida como aquilo de que é capaz um corpo na relação com outros ${ }^{16}$.

Neste contexto, experimentamos na intervenção os alcances de uma clínica-estética que, ao se abrir para a rua e para a arte, se amplia e se tece no território. Esta forma de clínica vai de encontro à estrutura manicomial, pois abandona o cuidado exclusivo de sintomas e busca a promoção da saúde de maneira ampla, impulsiona a criatividade e a capacidade de pensar e agir. A partir dela, é possível enxergar o processo saúde-doença como parte natural da vida, cuja vulnerabilidade não é um empecilho, mas a possibilidade de se abrir para as pessoas e para o mundo ${ }^{11}$.

Na proposição dessa clínica-estética, no encontro com a arte vamos encontrando formas de resistência às capturas psiquiatrizantes e ao apostarmos na potência criativa dos convivas, testemunhamos que mesmo em corpos excessivamente medicalizados há quem grite: “a arte resiste aqui!”. Essa frase foi inserida por uma conviva na versão antimanicomial inspirada na música O pulso dos Titãs, que inventamos no processo de construção do Circuito e virou uma das trilhas sonoras da intervenção estética:

Lítio, haldol, neuleptil, esquizofrenia / TOC, embotamento, depakote, catatonia / Biperideno, topiramato, agitação, histeria / Risperidona, olanzapina, amplictil, letargia / E a mente ainda sente.../ A arte resiste aqui! 
A estrofe sintetiza a resistência à lógica reducionista, psiquiatrizante e medicalizante que fundamenta a luta antimanicomial em sua diretriz ético-estética-política. Mais do que isso, é a afirmação de que o corpo ali está, vive, canta, dança, enfim, cria e expressa-se a despeito da anestesia que frequente e historicamente silencia o louco, a loucura na vida social. A versão da música, escrita por uma trabalhadora da RAPS (colaboradora do CECCO) e com o desfecho final 'A arte resiste aqui!' inserido por uma conviva, nos revela que, apesar da fuga do pensamento produzida pelos excessos de medicamentos, a mente sente e a arte ainda resiste como força pulsante afirmativa do viver frente à medicalização, efeito de um regime biopolítico de controle dos corpos e da vida através de diagnósticos e prescrições, que se reproduz na vida social capitalística em sentido amplo9.

A música foi gravada com os convivas, para a maioria vivenciando pela primeira vez a experiência de estar em um estúdio musical, e apresentada como trilha sonora da intervenção estética, dando o tom para nossa 'versão' antimanicomial da clássica história do Pequeno Príncipe.

\section{Primeiro ato: a Galeria de Arte B-612}

Embalados ritmicamente pelo pulso da conhecida música dos Titãs, convidamos agora o leitor a se imaginar perambulando pela Ribeira, histórico bairro de Natal, e se deparando com uma Galeria de Arte. Inserida em meio a prédios e ruas antigas, a Galeria B-612, nome em homenagem a obra de Exupéry, lhe convida ao encontro com uma diversidade de expressões artísticas: a pintura, a escultura, a arquitetura, destacandose obras que remetem à história da própria cidade do Natal.

Palco inicial do Circuito "O Pequeno Príncipe Ocupa a Ribeira", tal Galeria foi o primeiro planeta, nosso ponto de partida. Já na chegada, o visitante se deparava com quatro convivas recepcionando o público, inspirados nos planetas de Saint Exupéry: havia uma astrônoma e sua luneta, um homem de negócios e sua maleta, a rainha e sua realeza e a geógrafa e seus mapas. Pisando em tapetes feitos com caixas de medicamentos psicotrópicos, o visitante era acolhido e "carimbado" com um código de barras. Recepção essa que fazia ver e ouvir a experiência da medicalização da vida em cada um que chegava. Assim, no seio de um bairro histórico da cidade, parte da história da loucura local podia ir sendo desfeita um pouco e aqueles usualmente taxados como "loucos" convidaram para adentrar um "outro planeta", o planeta da convivência e da cultura para todos e cada um, e embarcar em uma viagem de problematização das lógicas psiquiatrizantes e medicalizantes da vida.

\section{Segundo ato: $o$ encontro do Pequeno Príncipe e a Rosa}

- Rosa, essa gente é muito estranha!! Não vive sem súditos, perde tempo fazendo cálculos, descrevendo tudo o que existe no mundo, mas sem realmente conhecer, encontrar, se afetar... Imagina só, como eu poderia descrever, falar sobre você, sem antes termos nos cativado?? (Trecho do Roteiro do Circuito "O Pequeno Príncipe Ocupa a Ribeira")

Nosso roteiro partia de onde o livro acabava: o retorno do Pequeno Príncipe ao asteróide B-612 (que no nosso caso era a Galeria), onde apresentamos a cena do reencontro entre o Principezinho, vindo das mais variadas aventuras no espaço infinito, e sua Rosa, que havia ficado solitária por todo esse tempo.

A Rosa, interpretada por uma conviva que emprestou o corpo para a expressão artística através de pintura corporal, figurino e adereços, está murcha a princípio - a potencialidade da conviva no uso das marcas de sua vida para expressar uma quase-vida da rosa sem o príncipe chama atenção: um corpo fetal, sem cor e sem palavras vai desabrochando, retomando à vida com o retorno do seu amigo, que há longo tempo não via.

Pensávamos na clínica hegemônica tradicional em seu excesso de descrições classificatórias e em como essa obsessão por dizer o que é, diagnosticar, acaba por negligenciar o principal que pode se passar em um encontro: a potência de cativar (afetar e ser afetado pelo outro).

\section{Terceiro ato: a vendedora de pílulas no planeta da medicalização}

Nosso Pequeno Príncipe se depara com uma mulher, vestida dos pés à cabeça com caixas de medicamentos, olhos pintados simetricamente com uma tarja preta, acompanhada de quatro companheiros, com vestimenta similar, carregando bandejas com pequenos copos. $\mathrm{O}$ grupo passa pelo público, convencendo a todos de maneira diretiva e alegórica: "- Tome sua pílula da felicidade!"

Ao som da nossa trilha sonora antimanicomial citada anteriormente, a cena vai se repetindo até que a Vendedora de Pílulas oferece o produto 
ao Pequeno Príncipe, e o mesmo vai questionado o porquê de todos estarem tomando a tal pílula: “- Vixe, como essa gente é estranha, usam até uma pílula para a felicidade!”.

O Príncipe debocha afirmando que o planeta da Galeria B-612 está muito pequeno para aquele povo todo e "tanta felicidade" e ele nos convida a sair da galeria e ocupar as ruas da Ribeira, carregados pelo cortejo percussivo e ao embalo do som do maracatu.

Os presentes na Galeria e os transeuntes são guiados pela rua por pássaros selvagens (referência de "O Pequeno Príncipe") / convivas batuqueiros em direção a outro ponto artístico cultural da cidade, a Casa da Ribeira. Em momento prévio ao início do circuito, um grupo de convivas havia deixado marcas em postes e muros abandonados com stencis em formato de rosas e raposas. Nesse trajeto, durante o cortejo, os curiosos e participantes do encontro deparavam-se com essas imagens e afetavam-se com a felicidade que também é possível aos loucos, ou ainda, que talvez só seja possível nas práticas de liberação das tentativas de normalização operadas pelo biopoder. Pelo caminho, ofertavam-se flores diversas aos transeuntes, que também eram impactados com um simples pedido: “- desenha uma rosa para mim?!”.

\section{Quarto ato: batuqueiros pássaros selvagens das emoções}

Quando o Pequeno Príncipe sai da Galeria (Planeta da Medicalização) rumo a conhecer novos lugares, nesse mesmo instante ele é tomado pelos novos pássaros selvagens, nossos batuqueiros. E, assim como no texto de Exúpery, no qual o Pequeno Príncipe é conduzido pelos pássaros através dos planetas, em nosso Circuito a percussão guiou essa ocupação pelas ruas da Ribeira.

Os batuqueiros são os convivas que participam da oficina de percussão e que sempre estão presentes em muitos eventos do CECCO, cujo poder cativante nas músicas culturais e de rua são destaque. Sons quase esquecidos pela sociedade ganham força, forma e movimento nas mãos dos batuqueiros - maracatu, samba-reggae, maculelê, coco. Em nossa intervenção estética, esse poder e vibração virou guia em ascendência e, assim como no texto de Exúpery, o Pequeno Príncipe foi conduzido pelos pássaros através dos planetas, em nosso Circuito a percussão guiou essa ocupação das ruas da Ribeira.

Cada batida de asa pulsando na batida do tambor, cada canto do nosso grito nas ruas, cada vibração gerada era nosso pouso e nossa marca nos planetas. Independentemente de qual fosse o motivo para a percussão existir ali, era uma prova de que estávamos vivos e gerando emoções. Se havia força nos gritos, haveria muito mais nas batidas. Se havia choro pelas estrelas caídas, haveria silêncio em nossas mãos. Cada batuqueiro na rua era um pássaro que transmite e expressa emoção. A experiência vai assim mostrando que todos, ditos loucos e ditos sãos, diagnosticados e não diagnosticados, podem aprender, ensinar, cativar, criar juntos.

\section{Quinto ato: o planeta \\ das mulheres rendeiras}

Durante o percurso do circuito, somos convidados a parar em frente à Delegacia das Mulheres. Lá, uma conviva ajoelhada no chão, tentando colar estrelas em sua renda, chora. Olha para o céu, chora e grita pelas estrelas "que estão caindo”, pelas florestas que estão sendo queimadas e destruídas, pelas mulheres e jovens, minorias que estão sendo assassinadas e violentadas. Chora por perceber sua impotência frente a tantas perdas.

Na cena, uma outra mulher rendeira se aproxima e pergunta o porquê de tanta tristeza. Após a explicação, oferece sua ajuda e de outras mulheres para juntas costurarem as estrelas no céu com um "fio de afeto". As rendeiras começam então a entoar: "- Olê mulher rendeira, olê mulher rendá, tu me ensina a fazer renda, que eu te ensino a lutar", enquanto outro conviva toca a melodia em sua viola/rabeca. Assim, todas as mulheres presentes são comovidas pela cena e as vozes se unem e se multiplicam ecoando nas ruas da Ribeira.... A cena é finalizada com a entrega de um vaso de flores de papel, ornamentado na oficina de artesanato do CECCO, pelas mulheres arteiras à delegada. E a caminhada é continuada até a Casa da Ribeira.

\section{O que podemos pensar da experiência: notas para o trabalho de desinstitucionalização}

A realização do Circuito demandou esforços de toda a equipe e convivas, assim como alterações no cotidiano do serviço. Todo o cronograma do CECCO foi reorganizado para que o tempo e as oficinas fossem direcionados à intervenção: algumas oficinas foram pausadas durante a execução do projeto; oficinas de artesanato, crochê e fuxico se concentraram na produção de cenários e figu- 
rinos; nas oficinas de dança e percussão ocorreram os ensaios das coreografias e músicas da apresentação; a oficina de teatro passou a ocupar um período mais longo do dia para construção de roteiro e ensaios.

Além disso, levamos muitas vezes o projeto para casa, de onde trouxemos estrelas e rosas com diversos materiais, ideias para cenas, doação de roupas e tecidos, entre outros; o Circuito ocupou a rotina e os pensamentos de todos. Desse modo, todo esse processo se constituiu em uma intervenção sobre a própria rotina do Centro, uma vez que modificou o funcionamento do serviço, conferindo maior autonomia e liberdade aos convivas e equipe para criar, pensar e se expressar.

A produção dessa intervenção-estética na cidade produziu, portanto, efeitos de desinstitucionalização no próprio serviço, que ao desacomodar sua organização cotidiana, sua "grade de horários de oficinas', vivenciou a abertura de um espaço para que algo diferente se criasse. Dessa experiência apreendemos que a desinstitucio- nalização não se dá sem uma certa disposição a entrar em contato com o caos, com a recusa a responder facilmente à pergunta "-mas o que é pra fazer?", colocada por muitos convivas e recolocando o questionamento de outro modo: “- mas o que podemos/queremos criar?"

O movimento que a intervenção estética gerou no coletivo de "descer do palco" em direção à rua se conecta com a torção da clínica que buscamos sustentar no cotidiano do CECCO. De uma lógica manicomial, que ao separar os sujeitos de seus contextos investe na separação da doença de seus processos de produção e assim acaba por desconsiderar cor, gênero, classe social, territórios de vida, se colocando de maneira transcendente e pretensamente neutra, buscamos nos distanciar para inventar uma clínica antimanicomial que através da força dos coletivos, da convivência e da arte, se conecte com o chão da cidade, construindo uma clínica que se dá na imanência com os territórios de existência dos convivas.

\section{Colaboradores}

JM Schenkel e GWS Silva participaram da concepção, delineamento, roteirização e execução da intervenção artística, bem como redigiram o relato de experiência e aprovaram a versão a ser publicada. AKMA Amorin, FAN Miranda e JBL Carvalho participaram da intervenção artística, colaboraram com a revisão crítica e aprovaram a versão a ser publicada. SEA Ribeiro, ACP Almeida e MM Silva participaram do delineamento, roteirização e execução da intervenção artística, bem como redigiram o relato de experiência e aprovaram a versão a ser publicada. 


\section{Agradecimentos}

Ao coletivo de convivas que fazem o Centro de Convivência e Cultura de Natal-RN acontecer. À Fundação Cultural Capitania das Artes, na pessoa do Diretor de Teatro Lenilton Teixeira dos Santos. À Galeria de Arte B-612, na pessoa do idealizador José Anchieta Miranda. Aos funcionários, colaboradores e voluntários: Francisca Jerusa Barbosa, Ivone Maria da Glória Alves Nogueira, Marcelle Janine Silva, Jacira Pereira Soares, Luiz de Siqueira Menezes Filho, Prof. Dr. Valmir de França, Profa. Inez Virley Rocha França, Carlos José Bernardo, Alessando Saraiva de Assis, Katia Ribeiro da Silva, Patrízia Daniele Selfes de Mendonça, Ilo Sérgio Rocha Costa e Íguia Telita de Medeiros Lima.

\section{Financiamento}

Universidade Federal do Rio Grande do Norte (códigos PJ910-2019, PJ092-2020, PJ253-2021).

\section{Referências}

1. Brasil. Ministério da Saúde (MS). Portaria no 3.088 de 23 de dezembro de 2011. Institui a Rede de Atenção Psicossocial para pessoas com sofrimento ou transtorno mental e com necessidades decorrentes do uso de crack, álcool e outras drogas, no âmbito do Sistema Único de Saúde (SUS). Diário Oficial da União 2011; 23 set.

2. Ferigato SH. Cartografia dos Centros de Convivência de Campinas: produzindo redes de encontros [tese]. Campinas (SP): Universidade Estadual de Campinas; 2013.

3. Brasil. Ministério da Saúde (MS). Lei no 10.216 de 6 de abril de 2001. Dispõe sobre a proteção e os direitos das pessoas portadoras de transtornos mentais e redireciona o modelo assistencial em saúde mental. Diário Oficial da União 2001; 6 abr.

4. Amorim AKMA, Severo AKS. Saúde mental, cultura e arte: discutindo a reinserção social de usuários da Rede de Atenção Psicossocial. Gerais (Univ. Fed. Juiz Fora) 2019; 12(2):282-299.

5. Pinheiro R, Guljor AP, Silva Jr AG. Necessidades e práticas na desinstitucionalização da clientela de longa permanência institucional: uma proposta de avaliação da relação entre demanda e oferta de cuidado. In: Pinheiro R, Silva Jr AG, Mattos RA. Desinstitucionalização da saúde mental: contribuições para estudos avaliativos. Rio de Janeiro: CEPESC: IMS/LAPPIS: ABRASCO; 2007.

6. Brasil. Ministério da Saúde (MS). Secretaria de Atenção à Saúde/DAPE. Saúde Mental no SUS: acesso ao tratamento e mudança do modelo de atenção. Relatório de Gestão 2003-2006. Brasília: MS; 2007. 85 p. [acessado 2020 out 14]. Disponível em: https://bvsms.saude. gov.br/bvs/publicacoes/relatorio_gestao_saude_mental_2003-2006.pdf

7. Liberato MTC, Dimenstein M. Arte, loucura e cidade: a invenção de novos possíveis. Psicol Soc 2013; 25(2): 272-281.

8. Amarante P, Torre EHG. Loucura e diversidade cultural: inovação e ruptura nas experiências de arte e cultura da Reforma Psiquiátrica e do campo da Saúde Mental no Brasil. Interface (Botucatu) 2017; 21(63):763-774.

9. Pelbart PP. Vida capital: ensaios de biopolítica. São Paulo: Iluminuras; 2003.

10. Foucault M. Une esthétique de l'existence (entretien avec A. Fontana). Le monde; 1984 juillet 15-16; p. 11 Tradução elaborada por Wanderson Flor do Nascimento.

11. Lima EMFA. Por uma arte menor: ressonâncias entre arte, clínica e loucura na contemporaneidade. Interface (Botucatu) 2006; 10(20):317-329.

12. Cunha CHP, Silva JC. O Beco da Quarentena: cenas de rasuras urbanas no texto-urbe. Interin (UTP) 2019; 24:121-138.

13. Osborne M. O Pequeno Príncipe. França: Paris Filmes; 2015.

14. Carreira A. Ambiente, fluxo e dramaturgia da cidade: materiais do Teatro de Invasão. O percevejo online 2009; 1(1). [acessado 2020 out 14]. Disponível em: http://seer.unirio.br/index.php/opercevejoonline/article/view/482 
15. Carreira A. Teatro performativo e a cidade como território. Revista Artefilosofia 2012; 12:5-15.

16. Deleuze G. Espinosa: filosofia pratica. Tradução de Daniel Lins e Fabien Pascal Lins. São Paulo: Escuta; 2002.

Artigo apresentado em 31/10/2020

Aprovado em 18/10/2021

Versão final apresentada em 20/10/2021

Editores-chefes: Romeu Gomes, Antônio Augusto Moura da Silva 